\title{
Shelf Life Degradation of Bulk Heterojunction Solar Cells: Intrinsic Evolution of Charge Transfer Complex
}

\author{
Antonio Guerrero $^{1}$, Hamed Heidari ${ }^{2}$, Teresa S. Ripolles ${ }^{1}$, Alexander Kovalenko, ${ }^{1, \&}$, \\ Martin Pfannmöller ${ }^{2}$, Sara Bals ${ }^{2}$, Louis-Dominique Kauffmann ${ }^{3}$, Juan Bisquert ${ }^{1,4}$, and \\ Germà Garcia-Belmonte ${ }^{1 *}$ \\ 1 Photovoltaic and Optoelectronic Devices Group, Departament de Física, \\ Universitat Jaume I, ES-12071 Castelló, Spain \\ 2 EMAT, University of Antwerp, Antwerp, Belgium \\ 3 Genes'Ink, 24 Avenue Gaston Imbert, 13790 Rousset, France \\ 4 Department of Chemistry, Faculty of Science, King Abdulaziz University, Jeddah \\ 21589, Saudi Arabia
}

\begin{abstract}
Achievement of long-term stability of organic photovoltaics is currently one of the major topics for this technology to reach maturity. Most of the techniques used to reveal degradation pathways are destructive and/or do not allow for real time measurements in operating devices. In this work, we combine three different, non-destructive techniques able to provide real-time information: namely, film absorbance, Capacitance-Voltage $(C-V)$ and Impedance Spectroscopy (IS), over a period of 1 year using non-accelerated intrinsic degradation conditions. It is discerned between chemical modifications in the active layer, physical processes taking place in the bulk of the blend from those at the active layer/contact interfaces. In particular, it is observed that during the ageing experiment the main source for device performance degradation is the formation of donor-acceptor charge transfer complex CTC $\left(\mathrm{P}_{3} \mathrm{HT}^{{ }^{++}-} \mathrm{PCBM}^{{ }^{-}}\right)$that acts as an exciton quencher. The generation of these radical species not only diminishes photocurrent but also reduces open-circuit voltage by the creation of electronic defect states. Conclusions extracted from absorption, $C-V$ and IS measurements will be further supported by a range of other techniques such as Atomic Force Microscopy, X-Ray Diffraction, and dark-field imaging of Scanning Transmission Electron Microscopy on ultrathin cross-sections.
\end{abstract}

Keywords: Organic photovoltaics, degradation, shelf life, charge transfer complex. 
\&Permanent address: Brno University of Technology, Faculty of Chemistry, Materials Research Centre, Purkyňova 118, 61200 Brno, Czech Republic

*Corresponding authors: A. Guerrero e-mail: aguerrer@uji.es, G. Garcia-Belmonte, e-mail: garciag@uji.es, tel.: +34 964 387548, fax: +34 964729218

19 January 2015 


\section{Introduction}

Research on materials and processing in organic photovoltaic (OPV) devices has led to impressive improvements over the last few years, with power conversion efficiencies (PCE) now reaching $10 \%$ for bulk heterojunction (BHJ) solar cells. ${ }^{[1]}$ In this type of devices, an interpenetrating matrix of donor and acceptor molecules harvests sun light and generates charges via photoinduced charge transfer that finally are collected at selective electrodes. ${ }^{[2]}$ Research in OPV has mainly been focused on three fronts: First, the design and synthesis of new semiconducting materials; ${ }^{[2-4]}$ second, the understanding on how the charge transfer and collection take place, and how interfacial effects limit the device efficiency; ${ }^{[5,6]}$ and, last but not least, closing the gap between laboratory achievements and industrial scale requirements. ${ }^{[7]}$ Long-term outdoor stability ${ }^{[8]}$ is one of the most challenging issues for building integrated applications with $>20$ years of durability.

In order to obtain further improvements in the stability of solar cells a detailed understanding of the device degradation mechanisms is required. ${ }^{[8]}$ Known degradation mechanisms include: diffusion of water ${ }^{[9]}$ and molecular oxygen ${ }^{[10],[11],[12]}$ into the device, chemical degradation of interfaces ${ }^{[12]}$ and active material, ${ }^{[13]}$ interlayer and electrode diffusion, ${ }^{[14]}$ or electrode reaction with the organic materials. ${ }^{[15]}$ However, other sources of performance degradation have been relatively unexplored as the intrinsic modification of chemical and morphological nature of active blend without intervention of external agents. In this direction, a recent study has shown that migration of polymer/fullerene molecules towards the electrodes during thermal ageing have been correlated with a loss in $V_{\text {oc }}$ for degraded devices. ${ }^{[16]}$ Hence one of the issues that still require intensive work is the understanding of specific mechanisms behind active layer intrinsic chemical evolution and its relationship to device performance. ${ }^{[17]}$

Adequate chemical and physical interactions between donor and acceptor molecules are required to provide efficient charge separation. Indeed, efficient separation of carriers takes place via delocalized charge transfer states ${ }^{[18,19]}$ where negative polarons in fullerene moieties ( $\left.P C B M^{\circ-}\right)$ seem to be strictly localized while positive polarons $\left(P 3 H T^{\bullet+}\right)$ are delocalized along a variable number of monomer units. ${ }^{[20]-[21]}$ Importantly, the polarizability of the charge transfer states depends on the crystallinity of the fullerene domains. ${ }^{[22]}$ Then chemical and morphological changes at the donoracceptor interface during device lifetime will directly affect the resulting photocurrent.

In this regard, it is already known from intentional degradation tests that the 
formation of localized charge transfer complexes CTC of $P 3 H T^{\bullet+}$ and oxidizing agents effectively reduces photocurrent. ${ }^{[11]}$ Charge Transfer complex is a generic term defined as an association of two or more molecules, in which a fraction of the electron charge is transferred from the donor to the acceptor in the electronic ground state. The resulting Coulomb attraction stabilizes the CTC. ${ }^{[23]}$ We can distinguish between strong CTC with full charge transfer usually called ion-radical salts, (they correspond to doping of the donor-acceptor material in terms of semiconductor physics with the formation of polaron states), and partial charge transfer of several degrees. In addition, full CTC can give rise to localized or delocalized charge (usually positive polarons or holes) that contribute to the polymer conductivity. After recognizing their importance more attention should be then paid to the detrimental role of donor-acceptor complexes (clearly observable in the absorption spectra of the blends) and how CTC degrades the device performance.

Under such a complete scenario it is usually not easy to discern on different degradation mechanisms in operating devices. A wide range of characterization techniques is available that can provide access to chemical and morphological variations in the device. ${ }^{[2]}$ For example, the structure and length scales of the donor-acceptor domains have been analyzed with techniques such as Atomic Force Microscopy $(\mathrm{AFM}),{ }^{[25-27]}$ (Scanning) Transmission Electron Microscopy $\left.((\mathrm{S}) \mathrm{TEM})\right)^{[28,29]}$ or Grazing Incidence X-ray Diffraction (GXID). ${ }^{[30]}$ For a comprehensive review the reader is referred to the work published by Pfannmöller et al. ${ }^{[31]}$ Alternatively, depth profile concentration of donor-acceptor blends has been obtained by using Variable-Angle Spectroscopic Ellipsometry (VASE), ${ }^{[32]}$ Near-Edge X-ray Absorption Fine Structure Spectroscopy (NEXAFS), ${ }^{[33]}$ Neutron Reflectivity, ${ }^{[34]}$ Dynamic Secondary Ion Mass Spectroscopy (SIMS), ${ }^{[35]}$ etc. However, many of these techniques are destructive and/or do not allow for monitoring real time chemical and morphology evolution of devices. Instead optical and electrical measurements have the potential to provide real time information on evolving devices, i.e. film absorption measurements can provide chemical $^{[11]}$ and morphology information, ${ }^{[36]}$ capacitance-voltage $(C$ - $V)$ offers access to defect density ${ }^{[37]}$ and fullerene content at the cathode, ${ }^{[38]}$ and Impedance Spectroscopy (IS) to series resistance, ${ }^{[39]}$ recombination kinetics ${ }^{[6]}$ and transport properties. ${ }^{[40]}$

The present work is focused on the use of these non-destructive techniques (absorption, $C-V$ and IS) to provide real time information about important efficiency degradation pathways very little studied previously: formation of donor-acceptor CTC 
$\left(\mathrm{P} \mathrm{HT}^{\bullet+}-\mathrm{PCBM}^{\bullet-}\right)$ that acts as an exciton quencher reducing the photocurrent, and also diminushes open-circuit voltage by the creation of electronic defect states. For this purpose, we will analyze the optical and electrical properties of P3HT:PCBM devices using non-accelerated ageing conditions: Encapsulated devices with inverted architecture were kept in the glovebox in the dark and were monitored during 1 year. Conclusions extracted from absorption, $C$ - $V$ and IS measurements are further supported by a range of other techniques such as Scanning TEM of cross-sections, EQE, AFM, and XRD.

\section{Experimental}

Solar cell fabrication. Devices were prepared in the inverted configuration ITO/ZnO/Active layer/ $\mathrm{MoO}_{3} / \mathrm{Ag}$. $\mathrm{ZnO}$ was diluted with IPA (1:1, vol:vol) and was spin coated in air at $2000 \mathrm{rpm}$ for 1 minute onto a pre-cleaned ITO coated glass substrate (10 $\mathrm{Ohm} / \mathrm{sq}$ ) to provide an average thickness of $\sim 50 \mathrm{~nm}$. The substrates were heated at $100^{\circ} \mathrm{C}$ for $5 \mathrm{~min}$ to dry the solvent and were transferred to a glovebox equipped with a thermal evaporator. $\mathrm{ZnO}$ was further thermally treated in the glovebox at $130^{\circ} \mathrm{C}$ for 10 min. The P3HT:PC ${ }_{60} \mathrm{BM}$ solutions were cooled down to R.T. 5 minutes before spin coating. Spin coating of the active layers were carried out as reported previously for P3HT:PCBM ${ }^{[41]}$ from o-dichlorobenzene (ODCB) as solvent to provide active layer thicknesses of $\sim 100 \mathrm{~nm}$. The device fabrication was completed by thermal evaporation of $10 \mathrm{~nm}$ of $\mathrm{MoO}_{3}$ and $100 \mathrm{~nm}$ of $\mathrm{Ag}$ as the anode under vacuum at a base pressure of $\approx$ $3 \times 10^{-6}$ mbar. Full devices were then encapsulated with epoxy and a glass slide before testing. Samples were taken outside the glovebox for $J-V$ and $C$ - $V$ measurements $(<15$ min) and were taken back to the glovebox and kept in the dark during the course of the experiment (1 year). Degradation conditions are milder than those used in ISOS-D-1 (Shelf) being the relative humidity controlled to a minimum by keeping the device in the glovebox at $\mathrm{H}_{2} \mathrm{O}$ levels below 1 ppm. ${ }^{[42]}$ To ensure that ambient exposure for short intervals of encapsulated devices did not interfere in the test some reference devices were kept in the glovebox for the whole period of study (one year period) and were measured only once at the end of the test. Efficiencies of these reference devices were within the dispersion of those encapsulated devices measured several times. Some nonencapsulated devices were kept in the glovebox for the whole period of the test to characterize the final state of the device using absorption and STEM measurements. 
Film and device characterization. Current density-voltage characteristics were carried out under illumination with a $1.5 \mathrm{G}$ source $\left(1000 \mathrm{~W} \mathrm{~m}^{-2}\right)$ using an Abet Sun 2000 Solar Simulator. The light intensity was adjusted with a calibrated Si solar cell. Capacitance-voltage and impedance spectroscopy measurements were performed using an Autolab PGSTAT-30 equipped with a frequency analyzer module. Capacitance was recorded by applying a small voltage perturbation $(20 \mathrm{mV} \mathrm{rms})$ at $1000 \mathrm{~Hz}$. Measurements were carried out in the dark at several bias voltages to extract the capacitance-voltage characteristics. The optical absorption spectra of the active layers were recorded by a Cary 500 Scan VARIAN spectrophotometer in the 300-2000 nm range using an integrating sphere. Further details on materials used and other characterization techniques (XRD, AFM, S-TEM) are provided as Supporting information.

\section{Results and discussion}

Shelf-life efficiency: $J$-V analysis.

In this work we aim at understanding morphology, chemical and active layer/contact interface modifications using non-destructive characterization techniques. For this purpose the evolution of device photovoltaic parameters upon shelf storage in the absence of oxygen, water or light is monitored. This methodology is used because all these agents are known to accelerate the degradation of BHJ solar cells. Under these conditions changes in performance are exclusively caused by chemical/morphological evolution of active layer blend and its interaction with contacts. An inverted configuration composed by ITO/ZnO/ $\mathrm{P} 3 \mathrm{HT}: \mathrm{PCBM} / \mathrm{MoO}_{3} / \mathrm{Ag}$ is chosen to minimize any degradation arising from the contacts. Devices are processed from odichlorobenzene (ODCB) as solvent, and they are kept in the glovebox under dark conditions over a period of one year only interrupted by regular measurements.

Fresh devices prepared using ODCB are known to provide an adequate morphology after a thermal treatment of the blend that enables an efficient charge separation, transport of carriers and collection at the electrodes. ${ }^{[43]}$ Our processing conditions assure efficiencies of about $3 \%$ for fresh devices. Representative J-V curves measured under illumination and in the dark are monitored as a function of the experiment time (Figure 1). S-shape curves are not observed and leakage current remains nearly constant. These two results suggest us that contact degradation is not severe in contraposition to other long term degradation studies where contact alteration is the main cause for 
performance decay. ${ }^{[4]}$

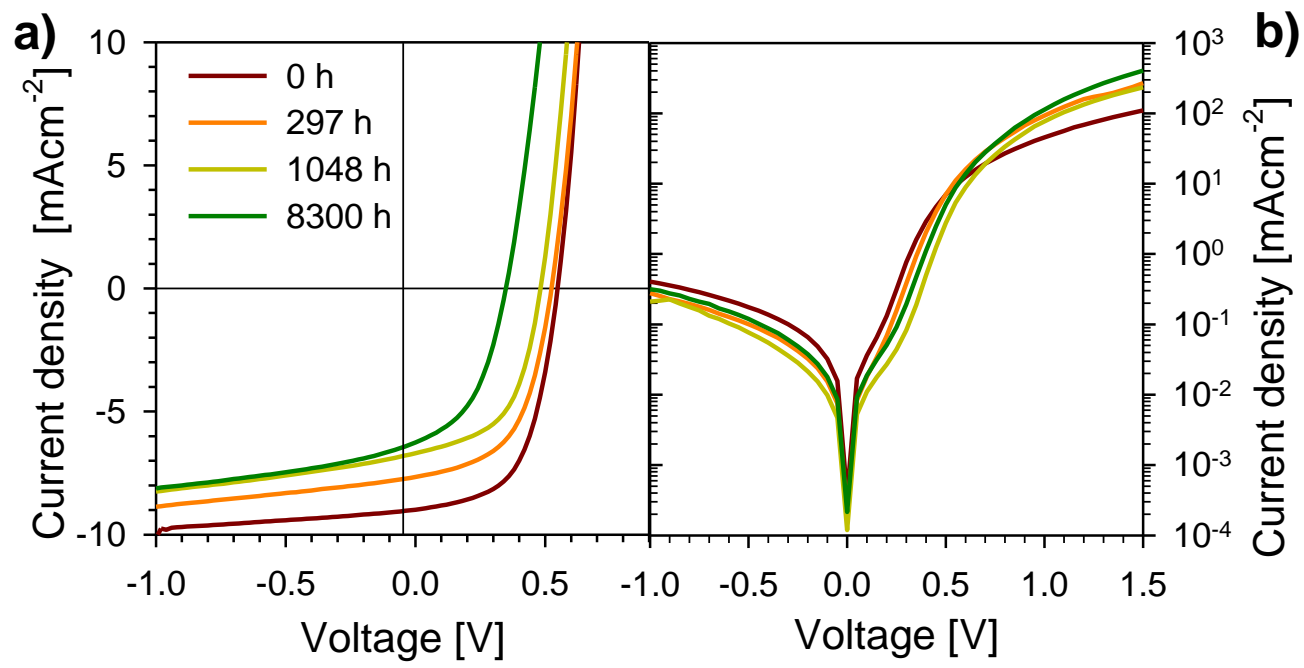

Figure 1: Representative J-V curves under illumination (a) and in the dark (b) as a function of the experiment time. $S$-shape curves are not observed and leakage current remains nearly constant both indicating that contacts do not degrade.

Devices showed a gradual reduction in efficiency (see Fig. 2) from about $3 \%$ to 1.5 $\%$ with shelf time decreasing all device parameters: The short circuit current $\left(J_{\mathrm{sc}}\right)$ by about $3 \mathrm{~mA} / \mathrm{cm}^{-2}$, the open circuit potential $\left(V_{\text {oc }}\right)$ by $150 \mathrm{mV}$ and the fill factor (FF) by $10 \%$. It is noticeable that all three photovoltaic parameters evolve following the same time profile. After approximately $1000 \mathrm{~h}$ of storage constant values are attained. Once this initial performance decay has taken place efficiencies remain rather constant. Indeed, Krebs et al. have tested the stability under outdoor conditions after this initial decay and shown that devices can be stable for at least another year if modules are properly encapsulated. ${ }^{[45]}$ Importantly by examining Fig. 2 one can infer that the evolution of all four photovoltaic parameters follow a similar trend. This would entail that a unique degradation mechanism is affecting the overall device performance. Unfortunately the information extracted solely from the $J$ - $V$ curves does not allow ascertaining detrimental causes underlying performance reduction. 


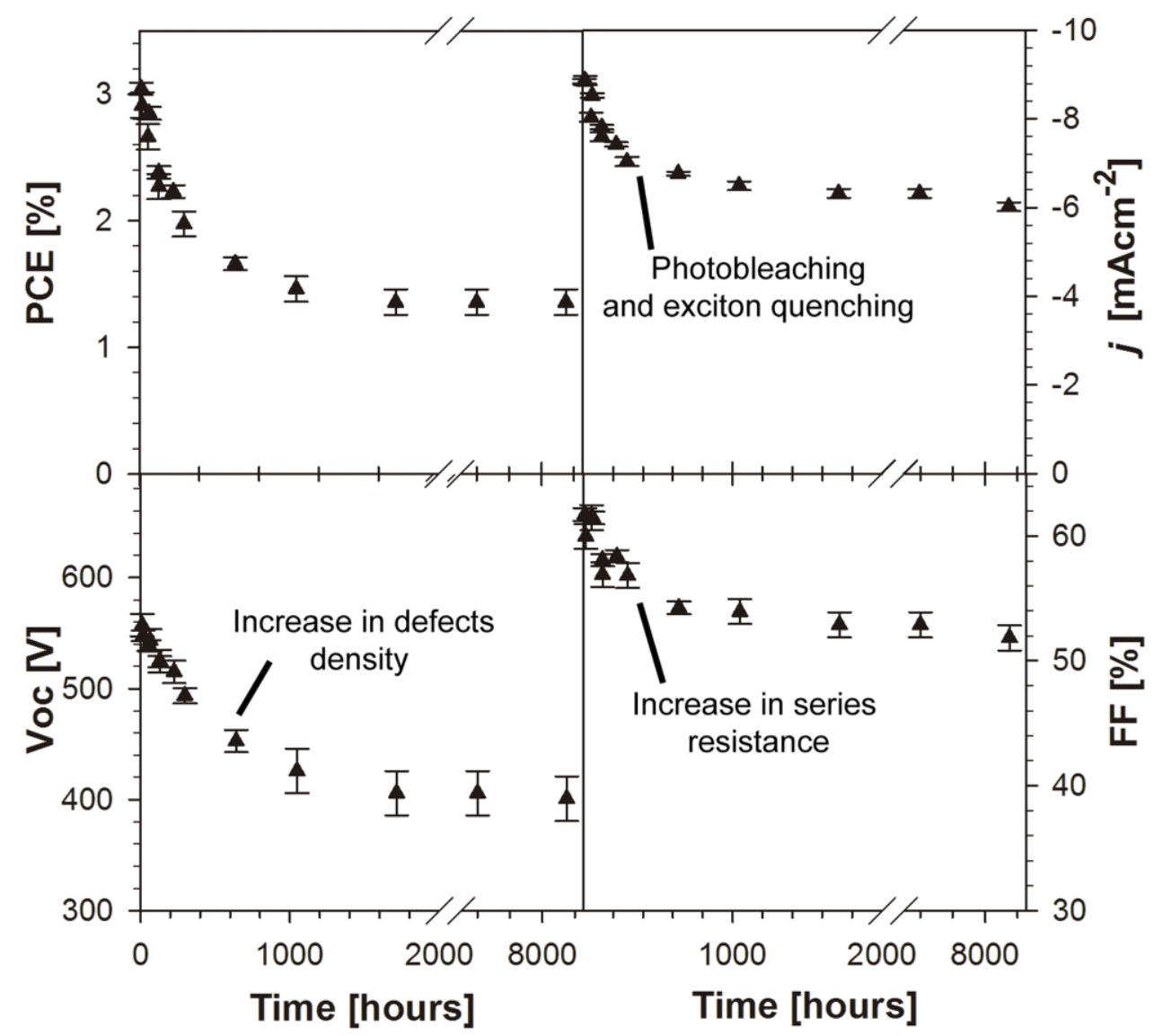

Figure 2: Device performance parameters extracted from $J-V$ curves measured during a period of 1 year for devices fabricated with the architecture $\mathrm{ITO} / \mathrm{ZnO} /$ $\mathrm{P} 3 \mathrm{HT}: \mathrm{PCBM} / \mathrm{MoO}_{3} / \mathrm{Ag}$ with active layer processed from ODCB.

\section{Optical Analysis of Fresh and Degraded Devices}

For examining photocurrent evolution it is important to note that it depends on a number of factors such as optical absorption of the active layer, charge separation and collection. By looking specifically to the absorption spectra of the film before and after the shelf life study (Figure 3a) it is observed that the intensity of both P3HT and PCBM main peaks below $650 \mathrm{~nm}$ decrease moderately. Therefore the absorption properties of the film decrease reducing the number of absorbed photons and consequently photocurrent. Quite remarkably a new band at 650-800 nm $(\sim 1.7 \mathrm{eV})$ appears in the aged sample while the intensity in the infrared region (from $1400 \mathrm{~nm}$ to $2000 \mathrm{~nm}$ ) slightly increases. The broad band at $\sim 900 \mathrm{~nm}$ does not modify the intensity being previously assigned to hole-polarons in the P3HT stabilized by $\mathrm{ZnO} .{ }^{[46]}$ Our proposal is that this new band at $650-800 \mathrm{~nm}$ originates from the increment in the $\left(\mathrm{P}_{3} \mathrm{HT}^{\circ+}\right.$ $\mathrm{PCBM}^{{ }^{-}}$) CTC density (see below). It is important to highlight that the new band at band is not related to a scattering effect as the measurements were carried out using an 
integrating sphere. Additionally, the crystallinity of the P3HT does not change significantly as inferred from the relative intensity of the absorption bands of P3HT and the XRD data (see Figure SI4a in Supporting Information). Accordingly no red shift in the main absorption peak or increment of vibronic shoulder intensity when comparing fresh and aged devices is observed.

Absorption bands above $650 \mathrm{~nm}$ usually correlate with the $P 3 H T^{\circ+}$ polaron formation, while the $\lambda_{\max }$ appears to depend on the nature of the oxidant. For example, the chemical oxidation of P3HT in the presence of oxidants such as oxygen ${ }^{[47]}$ or $\mathrm{NOBF}_{4}{ }^{[11]}$ provide $\lambda_{\max }$ values of $760 \mathrm{~nm}$ or $710 \mathrm{~nm}$, respectively. Here in order to better understand the nature of the new absorption band exhibited by aged devices (Figure 3a) polaronic species are generated by reaction of the P3HT:PCBM films with different concentrations of the oxidant $\mathrm{NOBF}_{4}$ as schematically drawn in Figure 3c. Corresponding absorption spectra are shown in Figure 3b. Interestingly two polaronic bands are produced that correlate with the polaronic bands for the CTC. Absorption spectrum for low $\mathrm{NOBF}_{4}$ concentration resembles that obtained for aged devices. Their peak position actually depend on the oxidant concentration. While $\lambda_{\max }$ of the high energy polaron band shifts from $800 \mathrm{~nm}$ at high $\mathrm{NOBF}_{4}$ concentration $(80 \mathrm{mM})$ to below $700 \mathrm{~nm}$ at low concentrations $(3 \mathrm{mM})$, the opposite trend is observed for the low energy maximum with $\lambda_{\max }$ changing from $1450 \mathrm{~nm}$ to values above $2000 \mathrm{~nm}$. This result clearly indicates that the properties of the actual CTC depends on the neighboring structural units. The higher concentration of polaronic species the more delocalized is the CTC as the absorption band at $\sim 700 \mathrm{~nm}$ is red shifted. One can therefore conclude that aging increases CTC concentration as evidenced from the similarity with polarons bands formed when external oxidant agents are used. It is important to note that formation of oxygen-related CTC is ruled out since encapsulated devices have been kept in the glovebox in the absence of oxygen. Further experiments are carried out to prove the absence of oxidation reactions as discussed below.

Recently the presence of the radical anion of $P C B M^{\circ-}$ have been detected using variable-temperature light-induced electron spin resonance in aged devices kept under static vacuum during nearly one month. ${ }^{[21]}$ Therefore, these considerations lead us to propose that the absorption band at $1.7 \mathrm{eV}$ is related to the generation of the donoracceptor $\mathrm{P}_{3} \mathrm{HT}^{\bullet+}-\mathrm{PCBM}^{\bullet-} \mathrm{CTC}$, as schematically depicted in Figure 3c. Generation of such a type of species would be in agreement with the observed reduction in the intensities of neutral PCBM and P3HT peaks which are consumed to generate the CTC. 
Very importantly, EQE measurements (shown in Supporting Information Fig. SI4) confirm that this CTC does not contribute to the photocurrent. Integration of the absorption spectra curves predicts a decrease in the maximum current of about $10 \%$, but the actual decrease in $J_{\mathrm{sc}}$ is about $35 \%$ (Table 1). Therefore there must be other factors contributing to the reduction in photocurrent. If we then take into account that the CTC is known to be an efficient exciton quencher, then a second factor responsible for the $J_{\mathrm{sc}}$ decrease is found. ${ }^{[48]}$ Importantly, this band is usually not observed using accelerated degradation conditions. ${ }^{[11,49]}$ 


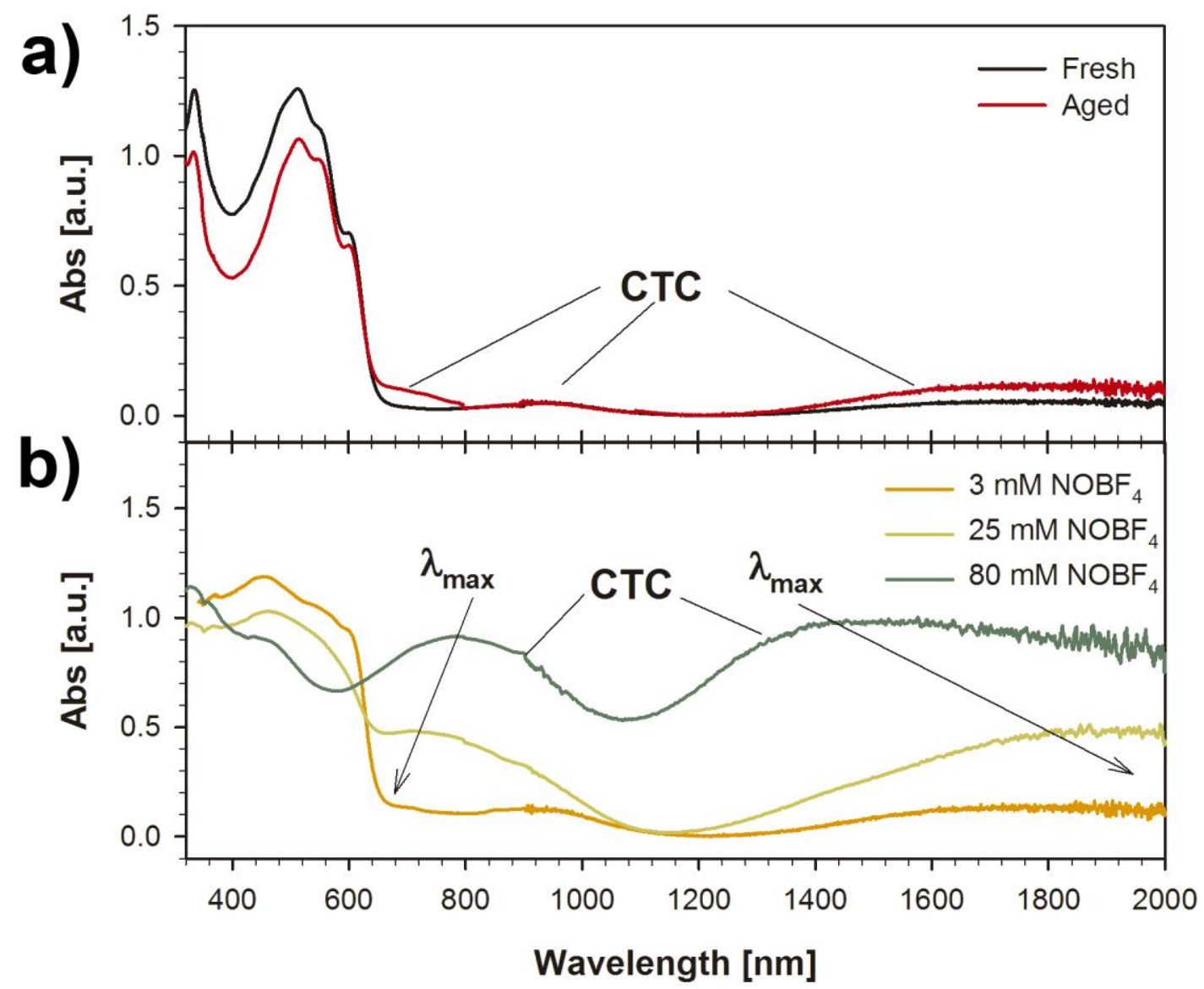

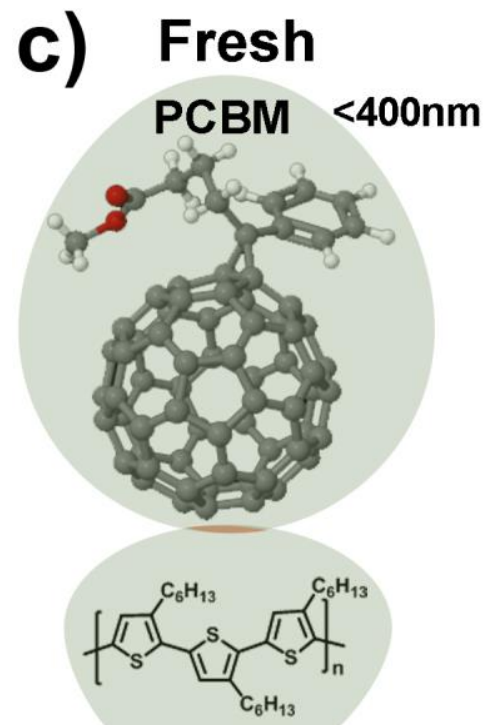

P3HT $\sim 400-650 \mathrm{~nm}$

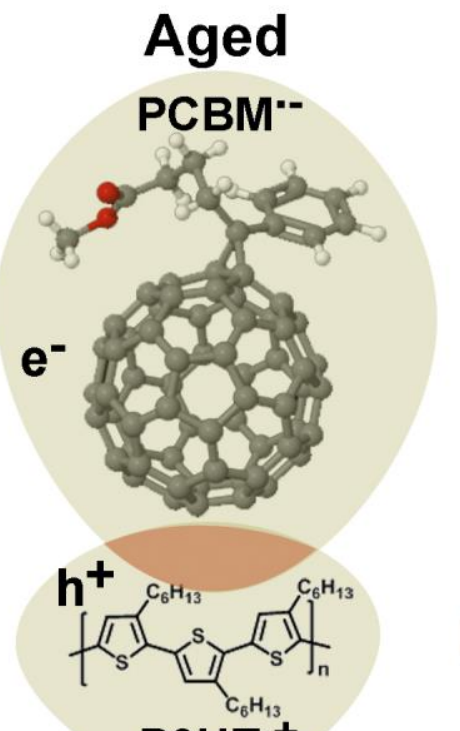

$\mathrm{P} 3 \mathrm{HT}^{\cdot+}>650 \mathrm{~nm}$

\section{Oxidation with $\mathrm{NOBF}_{4}$}
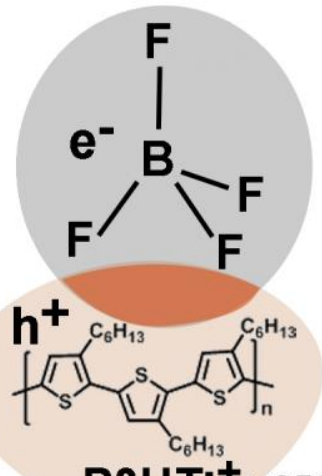

$\mathrm{P} 3 \mathrm{HT}^{*+}>650 \mathrm{~nm}$

Figure 3: (a) Absorption spectra of fresh and aged films cast from ODCB using integrating sphere. (c) Chemical structure of charge transfer complex and representative absorption bands for species present in the films for fresh and aged devices. The presence of the complex is negative for the device performance. 
To further discard the presence of oxygen, a degraded sample was thermally treated under nitrogen conditions with the intention to produce oxygen desorption as it is known to take place at temperatures of $120^{\circ} \mathrm{C}$ to recover neutral P3HT (see Supporting Information in Figure SI1). ${ }^{[50]}$ Here, we observe the absorption bands that correspond to neutral and the radical cation of P3HT does not change upon thermal annealing. Remarkably, temperature can be increased up to $220{ }^{\circ} \mathrm{C}$ for 3 hours and the morphology of the blend did not vary as inferred from the intensity ratio of the P3HT bands. However, the intensity of the PCBM bands decreases at temperatures above $130^{\circ} \mathrm{C}$ suggesting that dimerization of the PCBM molecules could have taken place. ${ }^{[17,51]}$ Interestingly, it is observed that dissolution on the active layer in ODCB does not occur as readily as it does for a freshly prepared samples annealed using the same conditions (see Figure SI1b in Supporting Information). Therefore the presence of these radical species appears to promote partial oligomerization of the fullerene molecules locking the morphology of the active layer. This final result would explain why the solar cell performance remains almost stable after the first $1000 \mathrm{~h}$.

\section{Electrical Analysis of Fresh and Degraded Devices}

As commented upon CTC formation entails electronic alterations in the absorbing layer. Capacitance-voltage $(C-V)$ technique can be used to measure electrically active defects present in the organic blend of complete devices. ${ }^{[37]}$ We have previously shown that energy level equilibration at the active layer/cathode interface generates a dipole layer at the cathode contact and band bending (depletion zone) in the adjacent active layer. ${ }^{\text {[52] }}$ From analysis of the Mott-Schottky behavior defect density $(N)$ and flat band potential $\left(V_{\mathrm{fb}}\right)$ can be extracted. Here, typical Mott-Schottky curves are also observed in all cases in agreement with previous reports (Supporting Information Figure SI2). ${ }^{[37]}$ The initial and final defect density values are listed in Table 1. 


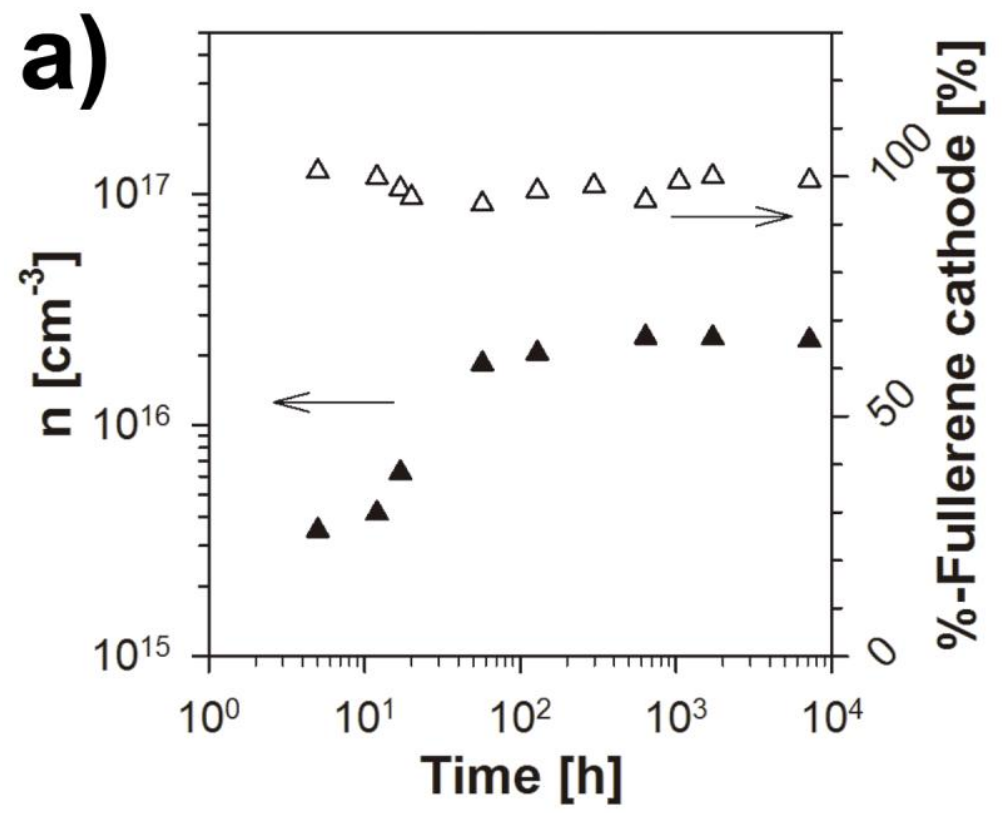

b) Pt sputtering

Ag

$\mathrm{MoO}_{3}$

P3HT:PCBM

Zno

ITO

Figure 4: (a) Evolution with shelf storage of defect density values $(N)$ and calculated fullerene content at the cathode interface extracted from capacitance-voltage measurements carried out in the dark of devices cast from ODCB. (b) STEM darkfield image of an ultrathin cross-section of a representative aged device that shows that contacts do not degrade over the lifetime.

\section{Table I}

Photovoltaic parameters for fresh and aged devices processed under different conditions. Optical and electrical parameters extracted from $J$ - $V$ curves, absorption measurements and capacitance-voltage are included. 


\begin{tabular}{ccccccc}
\hline & & \multicolumn{3}{c}{$N$} & \multicolumn{3}{c}{ Leakage Current } \\
Device & $\begin{array}{c}J_{s c} \\
\left(\mathrm{~mA} \mathrm{~cm}^{-2}\right)\end{array}$ & $\begin{array}{c}\text { Max } J s c a b s \\
\left.(\mathrm{~mA} \mathrm{~cm})^{-2}\right)\end{array}$ & $\begin{array}{c}V_{\mathrm{oc}} \\
\left(\times 10^{16} \mathrm{~cm}^{-3}\right) \\
(\mathrm{mV})\end{array}$ & $\begin{array}{c}\text { (dark }-1 V) \\
\left(\mathrm{mA} \mathrm{cm}^{-2}\right)\end{array}$ & $\begin{array}{c}\text { FF PCE } \\
(\%)\end{array}$ \\
\hline ODCB fresh & 8.8 & 11.8 & 0.3 & 557 & 0.4 & 613.04 \\
ODCB aged & 6.0 & 10.6 & 2.3 & 400 & 0.3 & 511.30
\end{tabular}

Devices processed from ODCB initially show low defect levels of about $3 \times 10^{15} \mathrm{~cm}^{-3}$ and these increase one order of magnitude after one year of shelf storage (about $2.3 \times 10^{16} \mathrm{~cm}^{-3}$ ). This increase in the defect density is gradual over the whole period of study as evidenced in Figure 4a. It is noted that the defect density maximum is reached after $1000 \mathrm{~h}$ of storage, a time that yields almost constant photovoltaic parameter values. Therefore, it seems to be a correlation between the CTC formation and the increment in defect density measured by $C-V$, indicating that defects may indeed be originated by the presence of donor-acceptor CTC. In previous works the intrinsic defect density correlate with the polymer crystallinity degree as measured by XRD and film absorption. ${ }^{\text {[3] }}$ However by observing absorption spectra in Fig. 3a of fresh and aged films one can infer that the polymer structural order is unaltered after the storage period. This leads us to regard donor-accpetor CTC as the source for the defect density increase, in which localized electrons in fullerene molecules act as acceptor impurities thereby enhancing the $p$-doping level. The proposed defect source is implies the delocalization of positive polarons along a variable number of monomer units. ${ }^{[20]-[21]}$ CTCs have then a certain probability to create mobile holes. In fact there is not a drastic separation between localized and delocalized CTC. Full ionization depends on the doping level and defect state energy. This would imply that a portion of CTCs are fully ionized promoting holes as quasi free carriers, precisely the portion that is detected using Mott-Schottky analysis. Similar arguments were discussed in our previous work ${ }^{[11]}$ where large reduction in the absorption band of P3HT only partially correlates with the increase in the defect level resulting from Mott-Schottky analysys. This is also in good accordance with Gregg's remarks on the charge localization degree of defect states ${ }^{[33,54]}$.

Regarding the $V_{\mathrm{oc}}$ decrease, we have recently shown that defect states within the effective bandgap modulate the downshift of the hole Fermi level under illumination that in turn establishes the achievable $V_{\text {oc }}{ }^{[43]}$ Then, it is proposed here that the observed 
increase in defect density is also responsible for the decrease in $V_{\mathrm{oc}}$. In order to understand if this is the only factor affecting $V_{\text {oc }}$ loss, possible contact degradation is checked as this has previously been shown to account for $V_{\text {oc }}$ reduction during ageing of devices. ${ }^{[55]}$ Here, dark-field STEM images of cross-sections confirm that the contacts are mechanically intact after the period of one year. An image of a representative degraded device is shown in Figure 4b. A comparable image of a fresh device is provided in the supporting information (Figure SI3). In none of the cases degradation of the inorganic layers or delamination was observed.

Relaying exclusively on electrical measurements, values of flat band voltage $V_{\mathrm{fb}}$ can be used to detect energetic modifications in the cathode contact. This parameter may provide information on the relative coverage of the cathode contact by fullerene/polymer molecules that ultimately determine the contact selectivity. Here, we analyze the fullerene content (Figure 4a) using the method previously reported by us, ${ }^{[38]}$ observing that no significant variation of the degree of fullerene coverage for samples cast from ODCB. The method is fully described in the Supporting Information. AFM analysis is also included which shows no significant differences between samples (Figure SI5). Additionally, we have also shown the relationship between the leakage current of the device and the fullerene content as measured from $C$ - $V$ measurements. ${ }^{[56]}$ In the previously reported work, high fullerene coverage of the cathode assures low leakage currents. Here leakage currents measured in the dark at $-1 \mathrm{~V}$ during the shelf life are nearly constant (Table 1), thus indicating that aged contacts show similar selectivity than fresh devices (Figure 1b). Therefore, the decrease in $V_{\text {oc }}$ is exclusively due to the increase in the defect density, and not to mechanisms connected to the contact degradation. This explains why $V_{\mathrm{oc}}$ and $J_{\mathrm{sc}}$ evolution with time exhibits similar trends. In both cases there is a gradual change in the film chemistry that promotes the formation of donor-acceptor CTC ( $J_{\mathrm{sc}}$ loss), with a concomitant defect density increase ( $V_{\mathrm{oc}}$ reduction).

Finally, impedance spectroscopy experiments have been carried out under illumination during ageing experiments. Here this technique is used to fully comprehend the evolution of resistive processes in devices. Impedance spectroscopy is able to discern between electrical processes taking place with different characteristic times/frequencies. In particular, recombination ${ }^{[6,41]}$ and resistive processes taking place at the contacts are observed at low frequencies, ${ }^{[40,56]}$ and transport of carriers in the high frequency region. ${ }^{[39,40]}$ Data fitting is performed using an equivalent circuit comprising 
two or three resistive contributions depending on whether contact effects are observable or not (see Supporting Information). Fresh samples processed with ODCB exhibit a resistive response dominated by the recombination properties with a small contribution from carrier transport. Representative spectra at different applied voltages and equivalent circuits are shown as Supporting Information (Figure SI6), and a summary of the fitting results is shown in Figure 5. Series resistances derive exclusively from transport $\left(R_{\mathrm{tr}}\right)$ mechanisms. Recombination kinetics can be analyzed in terms of recombination resistance $\left(R_{\mathrm{rec}}\right)$ and chemical capacitance $\left(C_{\mu}\right)$. It is important to recall that $R_{\text {rec }}$ is related to the recombination current derivative, ${ }^{[6]}$ therefore, high $R_{\text {rec }}$ are desired as this represents a higher opposition of the system to lose photogenerated carriers by recombination. Here a corrected voltage axis $V_{\mathrm{F}, \mathrm{sh}}$ is used to discount the voltage drop due to the series resistance with the aim of comparing devices under similar carrier densities (see Supporting Information for additional details). Interestingly, for the same $V_{\mathrm{F}, \mathrm{sh}}$ the extracted $R_{\text {rec }}$ value is higher for the fresh sample indicating that the aged samples exhibit higher charge recombination. This is an extra factor limiting the $V_{\mathrm{oc}}$.
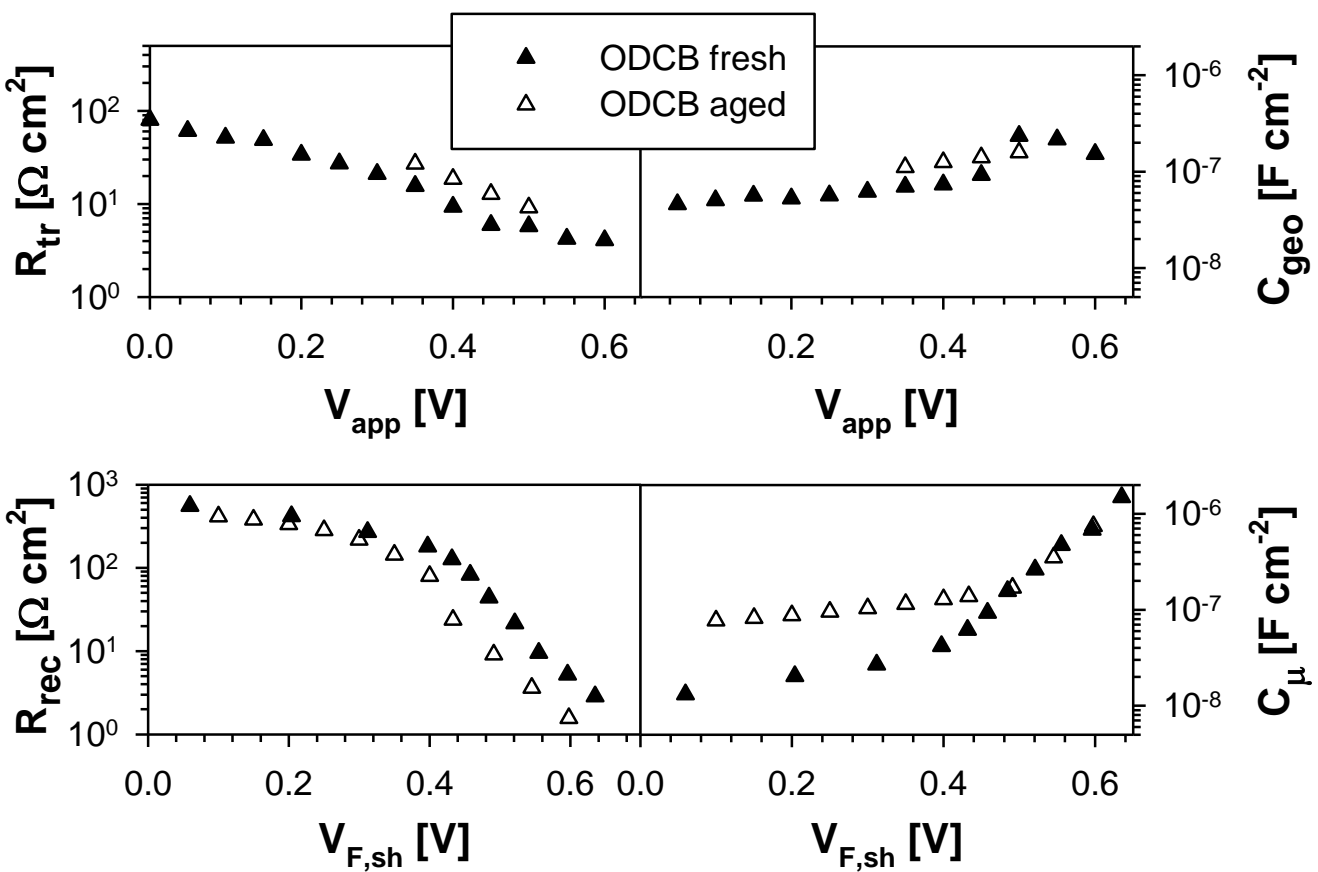

Figure 5: Fitting results extracted from impedance spectroscopy data for devices cast from ODCB. Representative devices have been measured fresh and at the end of the lifetime (aged). The equivalent circuits used are shown as supporting information. 
Regarding electrical contributions affecting FF, there are mainly two sources: the series resistance resistances associated to carrier transport $\left(R_{\mathrm{tr}}\right)$ and the voltagedependent recombination $\left(R_{\mathrm{rec}}\right)$. Figure 5 shows that both $R_{\mathrm{rec}}$ and $R_{\mathrm{tr}}$ exhibit worst values in the case of aged devices. ${ }^{[41]}$ It should be stressed that devices cast from ODCB do not show extra resistances associated to contact mechanisms indicating that extraction of carries is efficient for both fresh and aged devices, further supporting the high stability and unaltered selectivity of the contacts. Then, in ODCB-processed devices it appears that the presence of a relatively high concentration of defects states reduces the ability of the system to transport efficiently charge carriers (high $R_{\mathrm{tr}}$ ) then reducing FF.

\section{Conclusions}

A selection of physical techniques allows analyzing OPV degradation processes in real time using non-destructive methods. By analyzing the model system P3HT:PCBM processed from ODCB solvent we show long term performance evolution. It is feasible to distinguish between processes taking place at the outer interfaces to those occurring in the bulk of the blend. As a conclusion the degradation is entirely related to the formation of localized donor-acceptor CTC $\left(\mathrm{P} \mathrm{HT}^{\circ+}-\mathrm{PCBM}^{--}\right)$. Generation of CTC is responsible for photobleaching (exciton quenchers) with a concomitant increase in the density of electrically active defects. The generation of CTC species not only diminishes photocurrent by also reduces open-circuit voltage by the creation of electronic defect states. CTC have then a detrimental effect on the overall solar cell performance. If the OPV technology truly aims to achieve long term stability methods to avoid generation of such radical species needs to be developed.

\section{Acknowledgement}

This work was partially supported by FP7 European collaborative project SUNFLOWER (FP7-ICT-2011-7-contract num. 287594), and Generalitat Valenciana (project ISIC/2012/008 Institute of Nanotechnologies for Clean Energies). S.B. acknowledges financial support from European Research Council (ERC Starting Grant \#335078-COLOURATOMS). A.K. acknowledges Brno University of Technology for financial support (CZ.1.07/2.3.00/30.0039). M.P. gratefully acknowledges the SIM NanoForce program for their financial support. We would like to thank Dr. Beatriz Julián López for her support to carry out the absorption measurements using the 
integrating sphere.

\section{References}

[1] M. A. Green, K. Emery, Y. Hishikawa, W. Warta, E. D. Dunlop, Prog Photovoltaics 2012, 20, 12.

[2] G. Yu, J. Gao, J. C. Hummelen, F. Wudl, A. J. Heeger, Science 1995, 270, 1789.

[3] Y. Liang, Z. Xu, J. Xia, S.-T. Tsai, Y. Wu, G. Li, C. Ray, L. Yu, Advanced Materials (Weinheim, Germany) 2010, 22, E135.

[4] J. Peet, J. Y. Kim, N. E. Coates, W. L. Ma, D. Moses, A. J. Heeger, G. C. Bazan, Nature Materials 2007, 6, 497.

[5] A. Maurano, R. Hamilton, C. G. Shuttle, A. M. Ballantyne, J. Nelson, B. O’Regan, W. Zhang, I. McCulloch, H. Azimi, M. Morana, C. J. Brabec, J. R. Durrant, Advanced Materials (Weinheim, Germany) 2010, 22, 4987.

[6] P. P. Boix, A. Guerrero, L. F. Marchesi, G. Garcia-Belmonte, J. Bisquert, Advanced Energy Materials 2011, 1, 1073.

[7] F. C. Krebs, Sol. Energy Mater. Sol. Cells 2009, 93, 394.

[8] M. Jørgensen, K. Norrman, F. C. Krebs, Sol. Energy Mater. Sol. Cells 2008, 92, 686.

[9] K. Norrman, S. A. Gevorgyan, F. C. Krebs, ACS Applied Materials \& Interfaces 2009, 1, 102.

[10] F. C. Krebs, S. A. Gevorgyan, J. Alstrup, Journal of Materials Chemistry 2009, 19,5442 .

[11] A. Guerrero, P. P. Boix, L. F. Marchesi, T. Ripolles-Sanchis, E. C. Pereira, G. Garcia-Belmonte, Sol. Energy Mater. Sol. Cells 2012, 100, 185.

[12] M. O. Reese, A. J. Morfa, M. S. White, N. Kopidakis, S. E. Shaheen, G. Rumbles, D. S. Ginley, Sol. Energy Mater. Sol. Cells 2008, 92, 746.

[13] M. Manceau, A. Rivaton, J. L. Gardette, S. Guillerez, N. Lemaitre, Polymer Degradation and Stability 2009, 94, 898.

[14] H. J. Kim, H. H. Lee, J. J. Kim, Macromolecular Rapid Communications 2009, $30,1269$.

[15] C. F. Zhang, Y. Hao, S. W. Tong, Z. H. Lin, Q. A. Feng, E. T. Kang, C. X. Zhu, IEEE Transactions on Electron Devices 2011, 58, 835.

[16] I. T. Sachs-Quintana, T. Heumüller, W. R. Mateker, D. E. Orozco, R. Cheacharoen, S. Sweetnam, C. J. Brabec, M. D. McGehee, Advanced Functional Materials 2014, 24, 3978.

[17] Z. Li, H. C. Wong, Z. Huang, H. Zhong, C. H. Tan, W. C. Tsoi, J. S. Kim, J. R. Durrant, J. T. Cabral, Nat Commun 2013, 4. 
[18] A. A. Bakulin, A. Rao, V. G. Pavelyev, P. H. M. van Loosdrecht, M. S. Pshenichnikov, D. Niedzialek, J. Cornil, D. Beljonne, R. H. Friend, Science 2012, $335,1340$.

[19] A. E. Jailaubekov, A. P. Willard, J. R. Tritsch, W.-L. Chan, N. Sai, R. Gearba, L. G. Kaake, K. J. Williams, K. Leung, P. J. Rossky, X. Y. Zhu, Nature Materials $2013,12,66$.

[20] J. Niklas, K. L. Mardis, B. P. Banks, G. M. Grooms, A. Sperlich, V. Dyakonov, S. Beaupre, M. Leclerc, T. Xu, L. Yu, O. G. Poluektov, Physical Chemistry Chemical Physics 2013, 15, 9562.

[21] L. Bonoldi, C. Carati, L. Montanari, R. Po', The Journal of Physical Chemistry C 2014, 118, 7751.

[22] B. Bernardo, D. Cheyns, B. Verreet, R. D. Schaller, B. P. Rand, N. C. Giebink, Nat Commun 2014, 5, 3245.

[23] A. Y. Sosorev, D. Y. Paraschuk, Israel Journal of Chemistry 2014, 54, 650.

[24] W. Chen, M. P. Nikiforov, S. B. Darling, Energy and Environmental Science $2012,5,8045$.

[25] B. H. Hamadani, S. Jung, P. M. Haney, L. J. Richter, N. B. Zhitenev, Nano Letters 2010, 10, 1611.

[26] S. Mukhopadhyay, A. J. Das, K. S. Narayan, The Journal of Physical Chemistry Letters 2012, 4, 161.

[27] E. J. Spadafora, R. Demadrille, B. Ratier, B. Grévin, Nano Letters 2010, 10, 3337.

[28] M. Pfannmöller, H. Flügge, G. Benner, I. Wacker, C. Sommer, M. Hanselmann, S. Schmale, H. Schmidt, F. A. Hamprecht, T. Rabe, W. Kowalsky, R. R. Schröder, Nano Letters 2011, 11, 3099.

[29] S. S. v. Bavel, E. Sourty, G. d. With, J. Loos, Nano Letters 2009, 9, 507.

[30] J. Rivnay, S. C. B. Mannsfeld, C. E. Miller, A. Salleo, M. F. Toney, Chemical Reviews 2012, 112, 5488.

[31] M. Pfannmöller, W. Kowalsky, R. R. Schröder, Energy \& Environmental Science 2013, 6, 2871.

[32] M. Campoy-Quiles, T. Ferenczi, T. Agostinelli, P. G. Etchegoin, Y. Kim, T. D. Anthopoulos, P. N. Stavrinou, D. D. C. Bradley, J. Nelson, Nature Materials 2008, 7,158 .

[33] S. Zhu, Y. Liu, M. H. Rafailovich, J. Sokolov, D. Gersappe, D. A. Winesett, H. Ade, Nature 1999, 400, 49.

[34] D. Chen, A. Nakahara, D. Wei, D. Nordlund, T. P. Russell, Nano Letters 2010, 11, 561.

[35] C. M. Björström, S. Nilsson, A. Bernasik, A. Budkowski, M. Andersson, K. O. Magnusson, E. Moons, Applied Surface Science 2007, 253, 3906. 
[36] G. Li, V. Shrotriya, J. Huang, Y. Yao, T. Moriarty, K. Emery, Y. Yang, Nature Materials 2005, 4, 864.

[37] P. P. Boix, G. Garcia-Belmonte, U. Munecas, M. Neophytou, C. Waldauf, R. Pacios, Applied Physics Letters 2009, 95, 233302.

[38] A. Guerrero, B. Dörling, T. Ripolles-Sanchis, M. Aghamohammadi, E. Barrena, M. Campoy-Quiles, G. Garcia-Belmonte, ACS Nano 2013, 7, 4637.

[39] A. Guerrero, T. Ripolles-Sanchis, P. P. Boix, G. Garcia-Belmonte, Organic Electronics 2012, 13, 2326.

[40] A. Guerrero, S. Loser, G. Garcia-Belmonte, C. J. Bruns, J. Smith, H. Miyauchi, S. I. Stupp, J. Bisquert, T. J. Marks, Physical Chemistry Chemical Physics 2013, 15, 16456.

[41] A. Guerrero, L. F. Marchesi, P. P. Boix, J. Bisquert, G. Garcia-Belmonte, The Journal of Physical Chemistry Letters 2012, 3, 1386.

[42] M. O. Reese, S. A. Gevorgyan, M. Jørgensen, E. Bundgaard, S. R. Kurtz, D. S. Ginley, D. C. Olson, M. T. Lloyd, P. Morvillo, E. A. Katz, A. Elschner, O. Haillant, T. R. Currier, V. Shrotriya, M. Hermenau, M. Riede, K. R. Kirov, G. Trimmel, T. Rath, O. Inganäs, F. Zhang, M. Andersson, K. Tvingstedt, M. LiraCantu, D. Laird, C. McGuiness, S. Gowrisanker, M. Pannone, M. Xiao, J. Hauch, R. Steim, D. M. DeLongchamp, R. Rösch, H. Hoppe, N. Espinosa, A. Urbina, G. Yaman-Uzunoglu, J.-B. Bonekamp, A. J. J. M. van Breemen, C. Girotto, E. Voroshazi, F. C. Krebs, Sol. Energy Mater. Sol. Cells 2011, 95, 1253.

[43] T. S. Ripolles, A. Guerrero, G. Garcia-Belmonte, Applied Physics Letters 2013, 103, 243306.

[44] F. C. Krebs, K. Norrman, Prog Photovoltaics 2007, 15, 697.

[45] S. A. Gevorgyan, M. V. Madsen, H. F. Dam, M. Jørgensen, C. J. Fell, K. F. Anderson, B. C. Duck, A. Mescheloff, E. A. Katz, A. Elschner, R. Roesch, H. Hoppe, M. Hermenau, M. Riede, F. C. Krebs, Sol. Energy Mater. Sol. Cells 2013, 116, 187.

[46] P. Ravirajan, A. M. Peiró, M. K. Nazeeruddin, M. Graetzel, D. D. C. Bradley, J. R. Durrant, J. Nelson, The Journal of Physical Chemistry B 2006, 110, 7635.

[47] M. S. A. Abdou, F. P. Orfino, Y. Son, S. Holdcroft, Journal of the American Chemical Society 1997, 119, 4518.

[48] N. Grossiord, J. M. Kroon, R. Andriessen, P. W. M. Blom, Organic Electronics 2012, 13, 432.

[49] A. Seemann, T. Sauermann, C. Lungenschmied, O. Armbruster, S. Bauer, H. J. Egelhaaf, J. Hauch, Solar Energy 2011, 85, 1238.

[50] B. A. Mattis, P. C. Chang, V. Subramanian, Synthetic Metals 2006, 156, 1241.

[51] F. Piersimoni, G. Degutis, S. Bertho, K. Vandewal, D. Spoltore, T. Vangerven, J. 
Drijkoningen, M. K. Van Bael, A. Hardy, J. D'Haen, W. Maes, D. Vanderzande, M. Nesladek, J. Manca, Journal of Polymer Science Part B: Polymer Physics 2013, 51, 1209.

[52] A. Guerrero, L. F. Marchesi, P. P. Boix, S. Ruiz-Raga, T. Ripolles-Sanchis, G. Garcia-Belmonte, J. Bisquert, ACS Nano 2012, 6, 3453.

[53] Z. Liang, A. Nardes, D. Wang, J. J. Berry, B. A. Gregg, Chemistry of Materials 2009, 21, 4914.

[54] Z. Liang, B. A. Gregg, Advanced Materials 2012, 24, 3258.

[55] M. T. Lloyd, D. C. Olson, P. Lu, E. Fang, D. L. Moore, M. S. White, M. O. Reese, D. S. Ginley, J. W. P. Hsu, Journal of Materials Chemistry 2009, 19, 7638.

[56] A. Guerrero, N. F. Montcada, J. Ajuria, I. Etxebarria, R. Pacios, G. GarciaBelmonte, E. Palomares, Journal of Materials Chemistry A 2013, 1, 12345. 